\section{Identification of Apical and Cervical Curvature Radius of Human Molars}

Carlos Estrela', Mike R. Bueno², Fernando B. Barletta ${ }^{3}$, Orlando A. Guedes², Olavo C. Porto ${ }^{1}$, Cyntia R.A. Estrela ${ }^{2}$, Jesus Djalma Pécora ${ }^{4}$

\author{
'Department of Stomatologic \\ Sciences, - UFG - Universidade \\ Federal de Goiás, Goiânia, GO, Brazil \\ ${ }^{2}$ Department of Oral Sciences, \\ UNIC - Universidade de \\ Cuiabá, Cuiabá, MT, Brazil \\ 3Department of Endodontics, \\ ULBRA - Universidade Luterana \\ do Brasil, Canoas, RS, Brazil \\ ${ }^{4}$ Department of Endodontics, \\ USP - Universidade de São Paulo, \\ Ribeirão Preto, SP, Brazil
}

Correspondence: Prof. Dr. Carlos Estrela, Praça Universitária S/N, Setor Universitário, 74605-220 Goiânia, GO, Brasil. Tel: +55-62-3209-6254. e-mail: estrela3@terra.com.br

\section{Introduction}

Effective root canal preparation (RCP) is a determinant factor for the success of all subsequent procedures, e.g., root canal debridement, placement of intracanal medication and canal geometry optimization for filling (1). Peters (1) summarizes the main challenges of RCP in three aspects: 1) identification, access and enlargement of the main canals without procedural errors; 2) establishment and maintenance of adequate working lengths throughout the shaping procedure; and 3) selection of preparation sizes and overall geometries that allow adequate disinfection and subsequent filling. In this sense, knowledge of root canal morphology is the first requirement for a successful root canal treatment $(2,3)$. Several anatomical characteristics, e.g., number of canals, cross-sections, root canal curvatures, shape and position of apical foramina, ramifications and development disorders should all be carefully analyzed by the clinician to avoid unexpected events during RCP (2-7).

Up to a few years ago, the great challenge was to prepare a curved root canal with no ledge formation, foramen transportation, loss of working length or deviation from the original canal path, in addition to preventing accidents such as root perforation or instrument fracture. All these aspects motivated the performance of several studies of canal curvatures (8-16). However, in the last few years, endodontics has moved towards new directions, with a focus on new technologies in RCP, in particular nickel-titanium instruments (1). Today, undergraduate students in clinical training use nickel-titanium rotary instruments as routine and perceive better results in root canal treatment (17).

Periapical radiographs are routinely used in root canal treatment. The anatomical complexities of human molars, their nuances and peculiarities, highlight the care required during RCP of these teeth, especially in view of the frequent presence of curved canals. For many years, researchers have studied and proposed methods to determine the curvature of root canals, using either the angle or the radius of curvature method in periapical radiographs $(4,8-16)$. However, important limitations of this diagnostic imaging method have been described, especially because it generates a two-dimensional image of a three-dimensional structure $(3,7,16-18)$. Conebeam computed tomography (CBCT), in turn, has been increasingly used to identify anatomical and pathological alterations and has opened new perspectives when compared to conventional imaging exams (18).

The objective of the present study was to determine the frequency of apical and cervical curvatures in human molars using the radius method and $\mathrm{CBCT}$ images.

\section{Material and Methods Image Selection}

This study was developed using images from the database of private radiology clinics (CROIF, Cuiabá, 
MT, Brazil; and CIRO, Goiânia, GO, Brazil). Patients were referred to the clinics for different diagnostic reasons. A consecutive sample of 400 maxillary and mandibular first and second molars was selected among $\mathrm{CBCT}$ images from 328 patients (112 males and 216 females; mean age: 39.9 years).

Inclusion criteria for image selection were: highresolution $\mathrm{CBCT}$ images of maxillary and mandibular first and second molars longer than $20 \mathrm{~mm}$, with no previous endodontic treatment, no post and core placement, no calcified root canals or internal/external root resorption, and presence of a fully formed apex, with no history of orthodontic treatment, developmental disorders, or pathological processes.

A total of 1,200 root canals were evaluated. In mandibular molars, mesiobuccal (MB), mesiolingual $(\mathrm{ML})$, and distal (D) root canals were considered, while in the maxillary molars, $M B$, distobuccal (DB), and palatal (P) root canals were analyzed. In $\mathrm{D}$ root canals showing bifurcation into two canals, only the most curved root canal was selected for analysis. C-shaped root canals were excluded. The study design was approved by UFG Ethics Committee (Process \# 7968214.8.0000.5083).

\section{Imaging Method}

CBCT images were obtained using a PreXion 3D (PreXion 3D Inc., San Mateo, CA, USA), thickness: 0.100 $\mathrm{mm}$ (dimensions $1.170 \times 1.570 \times 1.925 \mathrm{~mm}$, FOV: $56.00 \mathrm{~mm}$, voxel $0.100 \mathrm{~mm}, 33.5 \mathrm{~s}$ [1024 views]). Tube voltage was $90 \mathrm{kVp}$ and tube current, $4 \mathrm{~mA}$. Exposure time was 33.5 s. Images were examined with the scanner's proprietary software PreXion 3D Viewer (TeraRecon Inc, Foster City, CA, USA) in a PC workstation running Windows XP professional SP-2 (Microsoft Corp., Redmond, WA, USA), with processor Intel Core 2 Duo E6300 1.86 Ghz (Intel Corp., Santa Clara, CA, USA), NVIDIA GeForce 6200 turbo cache videocard (NVIDIA Corporation, Santa Clara, CA, USA), and Monitor EIZO-Flexscan S2000, resolution $1600 \times 1200$ pixels (EIZO NANAO Corp., Hakusan, Japan).

\section{Determination of Radicular Curvature Radius}

The frequency of curved root canals was determined on CBCT images using a method previously described (16). Briefly, the curvature radius was determined in two regions of the root canal, namely the apical third (starting from the apical foramen) and the cervical third (starting from the canal entrance), and in two planes (coronal and sagittal).

First, the curvature radius of the apical region was calculated, followed by the curvature radius of the cervical region. This method uses two semi-straight lines (line segments) superimposed to the root canal, where the primary line corresponds to the longer continuity of the apical region, and the secondary line to the middle and cervical thirds. Regardless of the length of the secondary line, only the $6 \mathrm{~mm}$ closest to the primary line are taken into consideration and the midpoint of each semi-straight line is determined. From this point, two lines perpendicular to the semi-straight lines are drawn until they meet at a central point, which is named the circumcenter (19). The distance between the circumcenter and the center of each semi-straight line constitutes the radius of the circumference and defines the magnitude of the curve. The semi-straight lines may be shorter or greater, depending on the curvature of each root canal.

The curvature length evaluated was $6 \mathrm{~mm}$, but in some cases it was necessary to draw an imaginary semi-straight line to establish the circumcenter, particularly when the root canal showed more than one curve or lower arches than established (Fig. 1).

Based on three mathematical points obtained and using the Planimp ${ }^{\circledR}$ software (CDT Informática, Cuiabá, MT, Brazil), curvature radii were calculated for both root thirds (apical and cervical) and in both planes (coronal and sagittal). Root canal curvature radius values were used to classify the root canal thirds as follows: 0 straight line (no curvature); 1 - large radius ( $r>8 \mathrm{~mm}$, mild curvature); 2 - intermediate radius ( $r>4$ and $r<8$ $\mathrm{mm}$, moderate curvature); and 3 - small radius $(r \leq 4 \mathrm{~mm}$, severe curvature) (16).

All CBCT exams were analyzed by two examiners (one endodontist and one radiologist, both with over 10 years of experience), which were previously calibrated using $10 \%$ of the sample. When disagreements were observed, consensus was reached by discussing results with a third observer.

\section{Statistical Analysis}

Data were analyzed using the Statistical Package for the Social Sciences (IBM Co., New York, NY, USA), including frequency distribution and cross-tabulation. Curvature scores were compared using the chi-square test. Significance was set at $5 \%$.

\section{Results}

Among the 1,200 assessed root canals, 92.75\% presented curved root canals in the apical third, and $73.25 \%$ in the cervical third as assessed using coronal plane images. Sagittal plane analysis yielded 89.75 and $77 \%$ of curved root canals in the apical and cervical thirds, respectively. Root canals with a large radius (mild curvature) were significantly more frequent when compared with the other categories $(p<0.05)$, regardless of root third or analyzed image plane.

Curvature values in the apical and cervical thirds of 

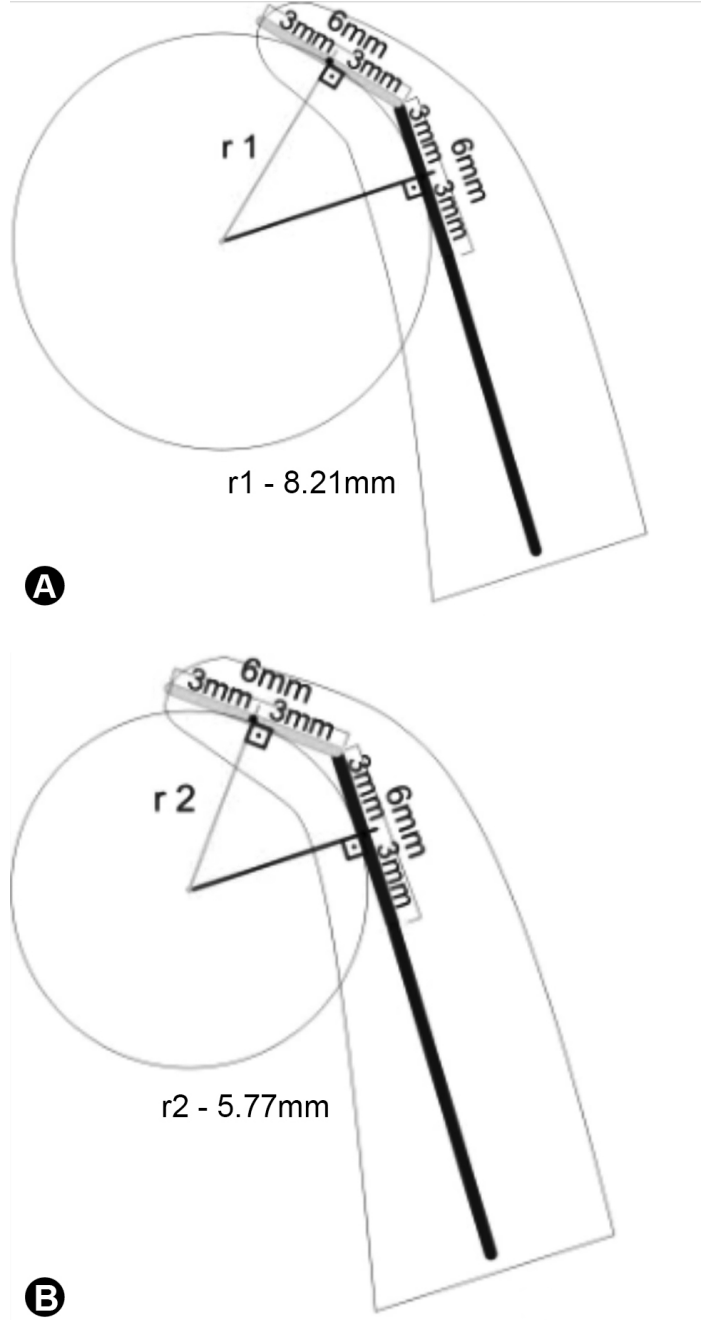

B

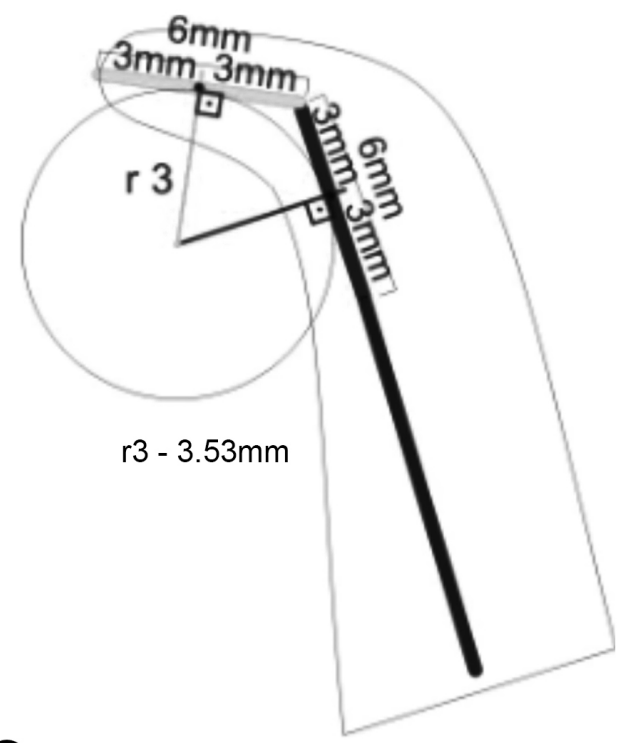

C

Figure 1. The root curvature radius based on 3 mathematical points can be determined in both apical and coronal directions. Curvature radius considering the two $6-\mathrm{mm}$ semistraight lines are classified as (16): small radius $(\mathrm{r} \leq 4 \mathrm{~mm})$ - severe curvature $(A)$; intermediary radius ( $r>4$ and $r \leq 8 \mathrm{~mm}$ ) - moderate curvature (B); and large radius $(r>8 \mathrm{~mm})$ - mild curvature (C).
$M B$ and $M L$ root canals of mandibular first and second molars did not show significant differences ( $p>0.05$ ) when analyzed in either the coronal or the sagittal plane. Conversely, the root canals of maxillary first molars showed differences $(p<0.05)$ in the cervical third in both the assessed planes (Tables 1 and 2). Figures 1 and 2 illustrate the method of determining curvature radii used in this study.

\section{Discussion}

The great majority of maxillary and mandibular molars showed root canals with some degree of curvature in both the apical and cervical thirds (Tables 1 and 2), a finding that is compatible with the literature $(8,13)$. High resolution of images, possibility to obtain images in different planes and segments, and dynamic navigation are some of the technological advancements brought forward by CBCT.

The frequency, degree of curvature, and configuration of $M B$ and $M L$ root canals of mandibular molars determined by radiographs in clinical and proximal directions showed curvature in both views. Secondary curvature, in a direction opposite to that of the principle curve, was seen more frequently in proximal view images. Proximal radiographs revealed greater mean curvatures than clinical images $38 \%$ of the time (8). Schäfer et al. (13) assessed canal curvatures in 700 extracted human permanent teeth by measuring the angle and radius of curvature and the length of the curved part of the canal, also in clinical and proximal views. All radiographs were analyzed using a computerized digital image processing system. The results showed that among the 1,163 root canals examined, $84 \%$ were curved.

The mesial root of mandibular molars has been well studied $(2,6,7,8,13)$. In the study sample, in coronal plane the apical thirds of MB and ML root canals of first and second mandibular molars were classified as showing moderate curvature (intermediate radius: $r>4$ and $r<8 \mathrm{~mm}$ ) in $21 / 22 \%$ and $24 / 19 \%$ of the specimens, respectively. In conventional imaging exams such as periapical radiography the $\mathrm{ML}$ root canal is usually poorly visualized, particularly in the sagittal plane.

One aspect worth mentioning is the higher frequency of cervical curvature found on sagittal images in the mesial root canals of mandibular molars and in $\mathrm{MB}$ and $\mathrm{DB}$ canals of maxillary molars (Tables 1 and 2). The negative influence of curved root canals has been a long-time concern in endodontics $(1,2,6-16)$. One way of dealing with this finding is to stabilize the apical curvature by cervical enlargement, which may avoid common drawbacks such as loss of working length, ledge formation, root perforation, and instrument fracture. In this sense, substantial advancements have been achieved in the 
quality of RCP after the advent of the new generation of nickel-titanium instruments with recognized flexibility (20-23). In addition, an innovative technique has been increasingly used to study root canal anatomy $(24,25)$ changes in canal geometry after $\operatorname{RCP}(21,22)$, namely, microcomputed tomography.

The comparison of different methods used to determine root curvatures was beyond the scope of this study. Rather, the aim was to use a previously described radius determination method $(16,23)$ and already adopted in clinical practice to analyze the frequency of curved root canals in different root thirds and planes using CBCT.

Previous studies have determined the curvature of root canals using the angle and the radius of curvature methods combined with periapical radiographs $(4,8-16)$. An angle-based well discussed classification of root

Table 1. Frequency (\%) of root canal curvature (scores 0-3) in cervical (C) and apical (A) thirds of first and second mandibular molars, in coronal and sagittal planes

\begin{tabular}{|c|c|c|c|c|c|c|c|c|c|c|c|c|c|}
\hline \multirow{2}{*}{ Teeth } & \multirow{2}{*}{ Scores } & \multicolumn{5}{|c|}{ Coronal Plane } & \multicolumn{7}{|c|}{ Sagittal Plane } \\
\hline & & MB-C & MB-A & ML-C & ML-A & $\mathrm{D}-\mathrm{C}$ & D-A & MB-C & MB-A & $\mathrm{ML}-\mathrm{C}$ & ML-A & $\mathrm{D}-\mathrm{C}$ & D-A \\
\hline \multirow{4}{*}{$\begin{array}{l}\text { MNFM } \\
(\mathrm{n}=100)\end{array}$} & 0 & 4 & 1 & 2 & 3 & 38 & 13 & 0 & 7 & 3 & 12 & 28 & 14 \\
\hline & 1 & 84 & 76 & 83 & 72 & 56 & 78 & 94 & 88 & 94 & 84 & 72 & 64 \\
\hline & 2 & 12 & 21 & 15 & 22 & 5 & 9 & 6 & 4 & 3 & 3 & 0 & 16 \\
\hline & 3 & 0 & 2 & 0 & 3 & 1 & 0 & 0 & 1 & 0 & 1 & 0 & 6 \\
\hline \multirow{4}{*}{$\begin{array}{l}\text { MNSM } \\
(\mathrm{n}=100)\end{array}$} & 0 & 0 & 0 & 0 & 0 & 79 & 9 & 0 & 4 & 1 & 5 & 30 & 10 \\
\hline & 1 & 85 & 73 & 84 & 80 & 20 & 84 & 92 & 75 & 93 & 77 & 70 & 56 \\
\hline & 2 & 15 & 24 & 16 & 19 & 1 & 7 & 8 & 10 & 6 & 8 & 0 & 20 \\
\hline & 3 & 0 & 3 & 0 & 1 & 0 & 0 & 0 & 11 & 0 & 10 & 0 & 14 \\
\hline
\end{tabular}

* Scores: 0 - straight line; 1 - large radius ( $r>8 \mathrm{~mm}) ; 2$ - intermediate radius $(r>4$ and $\mathrm{r}<8 \mathrm{~mm}) ; 3$ - small radius $(\mathrm{r} \leq 4 \mathrm{~mm})$. A = apical; $\mathrm{C}=$ cervical; $\mathrm{D}=$ distal; $\mathrm{MB}=$ mesiobuccal; $\mathrm{ML}=$ mesiolingual; $\mathrm{MNFM}=$ mandibular first molars; $\mathrm{MNSM}=$ mandibular second molars.

Table 2. Frequency (\%) of root canal curvature (scores 0-3) in cervical (C) and apical (A) thirds of first and second maxillary molars, in coronal and sagittal planes

\begin{tabular}{|c|c|c|c|c|c|c|c|c|c|c|c|c|c|}
\hline \multirow{2}{*}{ Teeth } & \multirow{2}{*}{ Scores } & \multicolumn{5}{|c|}{ Coronal Plane } & \multicolumn{7}{|c|}{ Sagittal Plane } \\
\hline & & MB-C & MB-A & DB-C & DB-A & $\mathrm{P}-\mathrm{C}$ & P-A & MB-C & MB-A & DB-C & DB-A & $\mathrm{P}-\mathrm{C}$ & P-A \\
\hline \multirow{4}{*}{$\begin{array}{l}\text { MXFM } \\
(n=100)\end{array}$} & 0 & 14 & 3 & 50 & 19 & 67 & 11 & 3 & 14 & 12 & 7 & 99 & 22 \\
\hline & 1 & 80 & 83 & 46 & 80 & 33 & 86 & 93 & 75 & 88 & 83 & 1 & 68 \\
\hline & 2 & 6 & 13 & 4 & 1 & 0 & 3 & 4 & 8 & 0 & 10 & 0 & 8 \\
\hline & 3 & 0 & 1 & 0 & 0 & 0 & 0 & 0 & 3 & 0 & 0 & 0 & 2 \\
\hline \multirow{4}{*}{$\begin{array}{l}\text { MXSM } \\
(n=100)\end{array}$} & 0 & 10 & 1 & 51 & 15 & 46 & 12 & 1 & 4 & 6 & 8 & 93 & 16 \\
\hline & 1 & 81 & 92 & 49 & 83 & 54 & 82 & 95 & 84 & 93 & 86 & 7 & 81 \\
\hline & 2 & 9 & 5 & 0 & 2 & 0 & 4 & 3 & 11 & 1 & 5 & 0 & 2 \\
\hline & 3 & 0 & 2 & 0 & 0 & 0 & 2 & 1 & 1 & 0 & 1 & 0 & 1 \\
\hline
\end{tabular}

* Scores: 0 - straight line; 1 - large radius ( $>8 \mathrm{~mm}) ; 2$ - intermediate radius $(r>4$ andr $<8 \mathrm{~mm}) ; 3$ - small radius $(\mathrm{r} \leq 4 \mathrm{~mm})$. $\mathrm{A}=\mathrm{apical} ; \mathrm{C}=\mathrm{cervical}$; $\mathrm{DB}=$ distobuccal; $\mathrm{MB}=$ mesiobuccal; $\mathrm{MXFM}=$ maxillary first molars; $\mathrm{MXSM}=$ maxillary second molars; $\mathrm{P}=$ palatal. 
canal morphology was suggested (4), with the following categories: I (straight), J (apical curve), C (completely curved), or S (multicurved). Nagy et al. (10) described root canal curvatures mathematically and suggested a standard model with the help of differentiated geometrical pattern analysis and computer graphics. Those authors analyzed 433 root canals by approximating measured points of the same radiographs using fourth degree polynomial functions describing the imaginary axis of canals. Schäfer et al. (13) examined 1,163 root canals and found a secondary curvature (S-shaped) in 17.5\% ( $n=204$; $12.3 \%$ of maxillary teeth and $23.3 \%$ of mandibular teeth). According to those authors, informing only the angle of curvature of root canals yields ambiguous results, as the curvature angle is independent of the curvature radius (canals with the same angle of curvature may have different radii). Therefore, in order to improve comparison across studies, curvatures should be described using both the angle of curvature, according to Schneider's method, and the radius and length of the curve. We agree with the conclusions of Schäfer et al. (13).

The focus of our study was to determine the frequency of curved root canals based on curvature radius in CBCT images. The method employed to determine curvature radius allows the analysis of a given segment of the root canal, and not necessarily its entire length. This is interesting because one root canal may present more than one curve, preventing correct radius calculation for the entire root length. In the present method, semi-straight lines can be shorter or longer, depending on the size of the curve analyzed in each root canal.

In sum, the curvature radius method used in the present study was easy, reproducible and can improve the planning of RCP in curved canals. The majority of root canals of maxillary and mandibular first and second molars showed some degree of curvature in the apical and cervical thirds, regardless of the analyzed plane (coronal or sagittal).

\section{Resumo}

Determinar a frequência de curvaturas apicais e cervicais em molares humanos usando o método do raio de curvatura e imagens de Tomografia Computadorizada de Feixe Cônico (TCFC). Quatrocentas imagens de primeiros e segundos molares superiores e inferiores foram selecionadas a partir de um banco de dados de exames de TCFC. 0 raio de curvatura dos canais foi medido usando um circuncentro com base em três pontos matemáticos e classificado de acordo com os seguintes escores: 0 - linha reta; 1 - raio grande ( $r>8 \mathrm{~mm}$, curvatura suave); 2 - raio intermediário ( $r$ $>4$ e $r<8$, curvatura moderada); 3 - raio pequeno ( $r \leq 4 \mathrm{~mm}$, curvatura severa). A frequência de curvaturas foi analisada em função do canal radicular, dos terços da raiz, e dos planos de avaliação (coronal e sagital); e avaliados usando o teste Qui-Quadrado (significância de $\alpha=0.05$ ). Dos 1200 canais radiculares avaliados, 92,75\% apresentaram curvatura no terço apical e $73,25 \%$ no terço cervical quando da análise no plano coronal; a
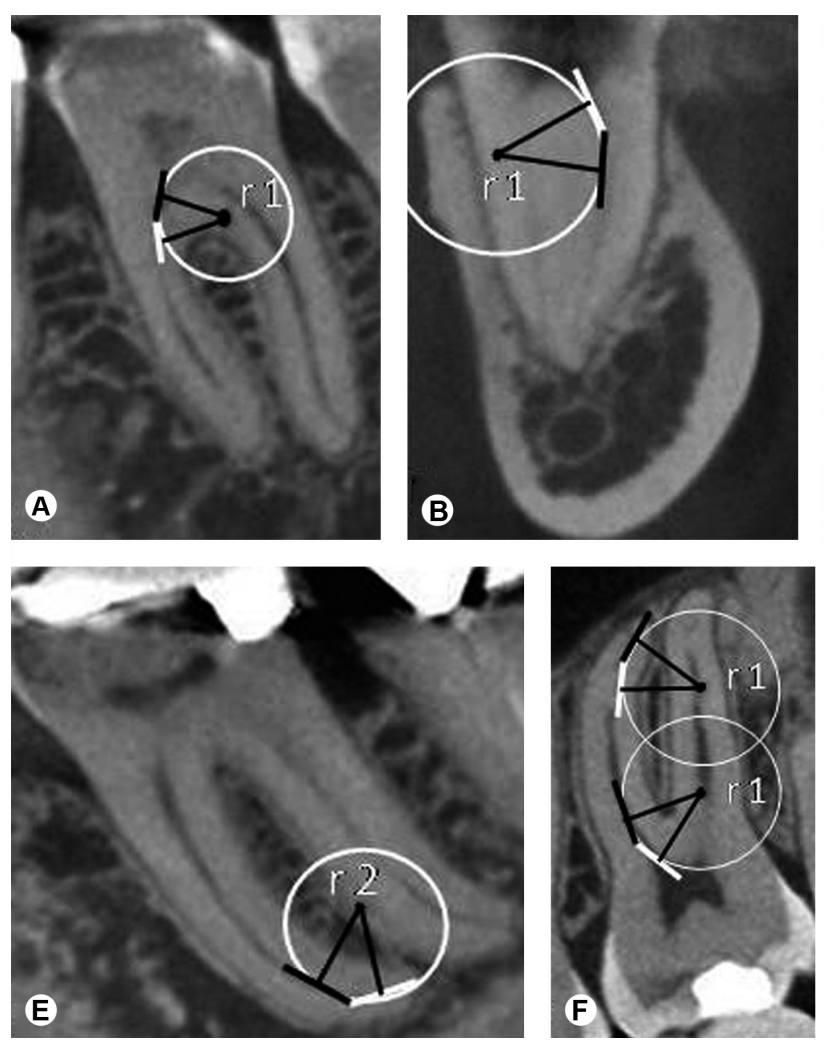
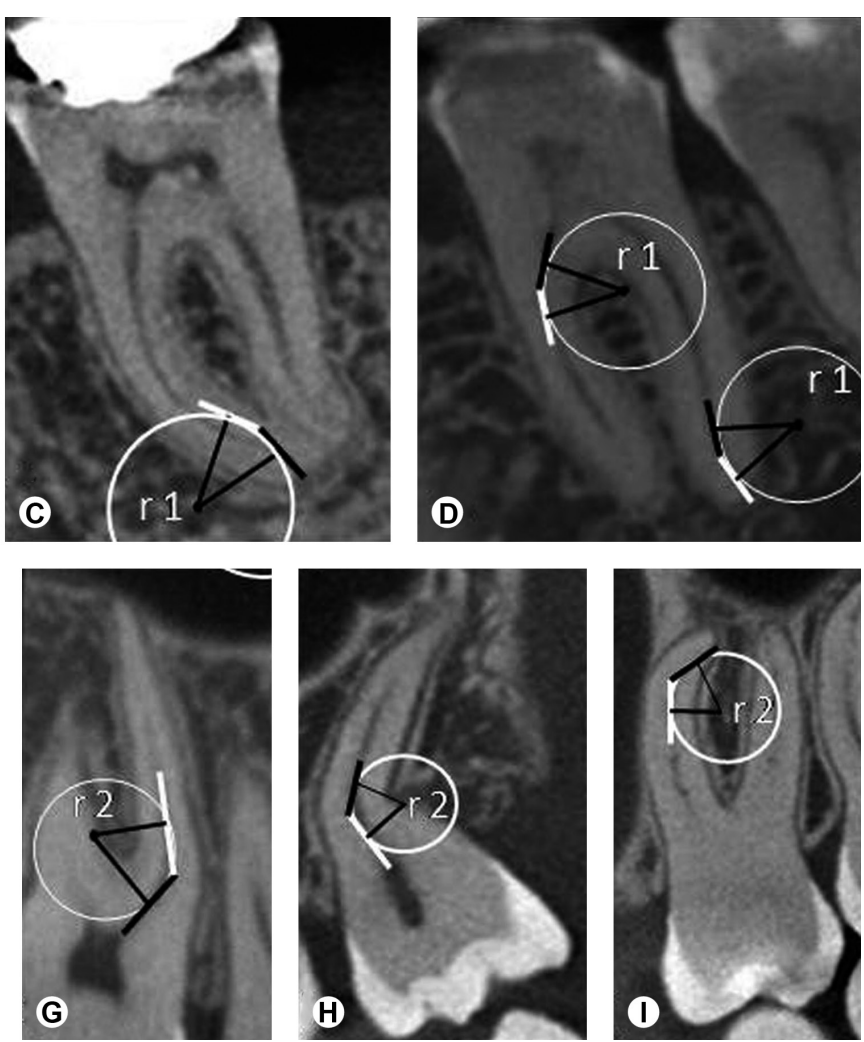

Figure 2 (A-l) lllustrations of curvature radii method showing cervical and apical curvature in sagittal and coronal planes in mandibular and maxillary molars. 
análise do plano sagital revelou $89,75 \%$ de canais curvos no terço apical e $77 \%$ no terço cervical. Canais radiculares com curvatura suave foram significantemente mais frequentes quando comparados com as demais categorias, independentemente do terço radicular ou do plano. A maioria dos canais radiculares dos primeiros e segundos molares superiores e inferiores apresentou algum grau de curvatura nos terços apical e cervical, independentemente do plano analisado (coronal ou sagital).

\section{Acknowledgements}

This study was supported in part by grants from the National Council for Scientific and Technological Development (CNPq grants 306394/2011-1 to C.E.).

\section{References}

1. Peters OA. Current challenges and concepts in the preparation of root canal systems: a review. J Endod 2004;30:559-567.

2. Vertucci FJ. Root canal morphology and its relationship to endodontic procedure. Endod Topics 2005;10:3-29.

3. Estrela $C$, Holland R, Estrela CRA, Alencar AHG, Sousa-Neto MD, Pécora JD. Characterization of successful root canal treatment. Braz Dent J 2014;25:3-11.

4. Schneider SW. A comparison of canal preparations in straight and curved root canals. Oral Surg Oral Med Oral Pathol 1971;32:271-275.

5. Schilder H. Cleaning and shaping the root canal. Dent Clin North Am 1974;8:269-296.

6. Leeb J. Canal orifice enlargements related to biomechanical preparation. J Endod 1983;9:463-470.

7. Pecora JD, Estrela C, Bueno MR, Porto OC, Alencar AHG, Sousa-Neto $M D$, et al.. Detection of root canal isthmuses in molars by mapreading dynamic using CBCT images. Braz Dent J 2013:24:569-574.

8. Cunningham CJ, Senia ES. A three dimensional study of canal curvatures in the mesial roots of mandibular molars. J Endod 1992;18:294-300.

9. Berbert A. Nishiyama CK. Root curvatures. A new methodology for mensuration and location. Rev Gaúcha Odontol 1994;42:356-358.

10. Nagy CD, Szabó J, Szabó J. A mathematically based classification of root canal curvatures on natural human teeth. J Endod 1995;11:557560.

11. Pruett JP, Clement DJ, Carnes DL. Cyclic fatigue testing of nickeltitanium endodontic instruments. J Endod 1997;23:77-85.

12. Lopes HP, Elias CN, Estrela C, Siqueira JF Jr. Assessment of the apical transportation of root canals using the method of the curvature radius. Braz Dent J 1998;9:39-45.

13. Schäfer E, Diez C, Hoppe W, Tepel J. Roentgenographic investigation of frequency and degree of canal curvatures in human permanent teeth. J Endod 2002;28:211-216.

14. Sonntag D, Stachniss-Carp S, Stachniss V. Determination of root canal curvatures before and after canal preparation (part 1): a literature review. Aust Endod J 2005;31:89-93.

15. Günday M, Sazak H, Garip Y. A Comparative study of three different root canal curvature measurement techniques and measuring the canal access angle in curved canals. J Endod 2005;31:796-798.

16. Estrela C, Bueno MR, Sousa-Neto MD, Pécora JD. Method for determination of root canal curvature radius using cone-beam computed tomography images. Braz Dent J 2008;19:114-118.

17. Alves RAA, Souza JB, Alencar AHG, Pécora JD, Estrela C. Detection of procedural errors with stainless steel and NiTi instruments by undergraduate students using conventional radiograph and cone beam computed tomography. Iran Endod J 2013;8:161-165.

18. Cotton TP, Geisler TM, Holden DT, Schwartz SA, Schindler WG Endodontic applications of cone beam volumetric tomography. J Endod 2007;33:1121-1132.

19. Boyer CB. A history of mathematics. 2nd ed. Revised by Merzbach UC. New York: Wiley; 1989.

20. Thompson AS. An overview of nickel-titanium alloys used in dentistry. Int Endod J 2000;33:297-310.

21. Peters $O A$, Laib $A$, Ruegsegger $P$, Barbakow F. Three-dimensional analysis of root canal geometry by high-resolution computed tomography. J Dent Res 2000;79:1405-1409.

22. Peters OA, Laib A, Göhring TN, Barbakow F. Changes in root canal geometry after preparation assessed by high-resolution computed tomography. J Endod 2001;27:1-6.

23. Capar ID, Ertas H, Ok E, Arslan H, Ertas ET. Comparative study of different novel nickel-titanium rotary systems for root canal preparation in severely curved root canals. J Endod 2014;40:852-856.

24. Versiani MA, Pecora JD, Sousa-Neto MD. Root and root canal morphology of four-rooted maxillary second molars: a microcomputed tomography study. J Endod 2012;38:977-982.

25. Versiani MA, Pecora JD, Sousa-Neto MD. Microcomputed tomography analysis of the root canal morphology of single-rooted mandibular canines. Int Endod J 2013;46:800-807.

Received April 30, 2015 Accepted June 25, 2015 